\title{
An empirical model for estimating phytoplankton productivity in estuaries
}

\author{
Brian E. Cole \& James E. Cloern \\ U. S. Geological Survey, 345 Middlefield Road, MS 496, Menlo Park, California 94025, USA
}

\begin{abstract}
We have previously shown that primary productivity in San Francisco Bay, USA, is highly correlated with phytoplankton biomass B (chlorophyll a concentration) and an index of light availability in the photic zone, $Z_{p} I_{o}$ (photic depth times surface irradiance). To test the generality of this relation, we compiled data from San Francisco Bay and 5 other USA estuarine systems (Neuse and South Rivers, Puget Sound, Delaware Bay and Hudson River Plume), and regressed daily productivity $\int \mathrm{P}\left(\mathrm{mg} \mathrm{C} \mathrm{m}^{-2} \mathrm{~d}^{-1}\right)$ against the composite parameter $\mathrm{B} \mathrm{Z}_{\mathrm{p}} \mathrm{I}_{0}$. Regressions for each estuary were significant and typically over $80 \%$ of the variation in $\int \mathrm{P}$ was correlated with variations in $B Z_{p} I_{0}$. Moreover, the pooled data $(n=211)$ from 4 estuaries where methodologies were comparable fell along one regression line $\left(\mathrm{r}^{2}=0.82\right)$, indicating that primary productivity can be estimated in a diversity of estuarine waters from simple measures of phytoplankton biomass and light availability. This implies that physiological variability (e. g. responses to variations in nutrient availability, temperature, salinity, photoperiod) is a secondary control on phytoplankton production in nutrient-rich estuaries, and that one empirical function can be used to estimate seasonal variations in productivity or to map productivity along estuarine gradients of phytoplankton biomass and turbidity.
\end{abstract}

\section{INTRODUCTION}

Much of our effort to understand the dynamics of phytoplankton populations has focused on the role of nutrients, short-term physiological variability, or light availability in controlling productivity of lakes and oceans. In estuaries, nutrient availability is generally adequate to support production, although the relative importance of different nutrient sources is unclear (Nixon 1981). Because estuaries are turbid and nutrient rich, light availability may be the most important factor controlling biomass-specific productivity (Cadée \& Hegeman 1974, Joint \& Pomroy 1981, Colijn \& Ludden 1983, Wofsy 1983). Therefore, photosynthetic carbon assimilation may be more amenable to prediction in estuaries than in oligotrophic waters where interactions between light and nutrients must be considered.

Several lines of evidence support this contention. (1) Many estuaries have horizontal gradients of increasing productivity in a seaward direction where turbidity decreases and light availability (photic depth) increases (Colijn 1978, Joint \& Pomroy 1981, Pennock 1983, Cloern et al. 1985), even though nutrient concentrations usually decrease seaward (Nixon 1981). (2) Estuarine sites with low suspended sediment levels (deep photic zones) have high areal production relative to more turbid locations (Cadée \& Hegeman 1974, Cadée 1978, Cole \& Cloern 1984, Peterson \& Festa 1984). (3) In many estuaries phytoplankton biomass and productivity increase during stratification events in which the mixed surface layer shallows, and mean irradiance exposure of the phytoplankton increases (Winter et al. 1975, Sinclair 1978, Haas et al. 1981, Cloern 1984). (4) Productivity of the whole phytoplankton population and 3 size fractions in San Francisco Bay is highly correlated with biomass and light availability (Cole \& Cloern 1984, Cole et al. 1986). Nutrient availability (instantaneous pools plus regeneration rate) may ultimately govern the upper limit to productivity during blooms, but seasonal and interannual variability of estuarine phytoplankton productivity may primarily be controlled by variations in phytoplankton biomass and irradiance in the mixed surface layer.

Phytoplankton can exhibit pronounced short-term (hourly to daily) variability in photosynthetic capacity (maximum assimilation rate and quantum efficiency; Harris 1978). However, this short-term physiological variability may not be relevant to problems that address long time scales such as weekly, seasonal or 
annual variations in primary productivity. From studies that have considered the mechanisms of such variations in productivity in lakes (Brylinsky \& Mann 1973), oceans (Platt 1986), and estuaries (Boynton et al. 1982), there is increasing evidence that physiological variations of phytoplankton are secondary to the variations in biomass, light availability, or nutrients. Brylinsky \& Mann (1973) found that for a broad spectrum of lakes and reservoirs chlorophyll a concentration combined with variables related to light energy constitutes a good estimator of primary productivity. Platt (1986) reports that in a variety of oceanic environments biomass-specific primary productivity is a linear function of surface irradiance. Boynton et al. (1982) suggested that estuarine phytoplankton productivity is high during warm periods of the year, and at times when ratios of nitrogen to phosphorus are low. No other attempts have been made to determine if common factors are responsible for variations in productivity among estuaries.

In previous papers (Cole \& Cloern 1984, Cole et al. 1986) we showed that primary productivity in the photic zone of San Francisco Bay is highly correlated with phytoplankton chlorophyll $a$ and light availability. In this paper we extend that approach and show that similar correlations hold in 6 diverse estuarine systems and a coastal estuarine plume. Based on this finding we infer that changes in phytoplankton productivity over periods of weeks to years and large geographic areas can be estimated simply in estuaries where nutrients do not limit production.

\section{METHODS}

The data used in this analysis are from 27 sites in 6 U.S. estuaries (Table 1) representing 3 estuary types: fjord, river-dominated (partially mixed), and lagoon, as well as an estuarine plume. Thus, the data are from systems that encompass a broad range of geomorphological and hydrographic diversity. The data were collected over extended periods and therefore also represent the temporal variability inherent in each system.

For each data set, measures of integral productivity $\int P$ within the photic zone (variable units) were regressed against an empirically derived parameter that is the product of phytopiankton biomass, $B\left(\mathrm{mg} \mathrm{m}^{-3}\right.$ chlorophyll a), the photic depth, $Z_{p}(m)$, and surface irradiance $I_{0}$ (variable units) over the duration of the incubation experiment. Photic depth was taken as the depth of $1 \%$ surface irradiance calculated from the measured light attenuation coefficient, $\mathrm{k}\left(Z_{\mathrm{p}}=4.61 / \mathrm{k}\right)$, or values of $\mathrm{k}$ estimated from Secchi depth $(\mathrm{m})$ using the relation $\mathrm{k}=0.4+1.09 /$ Secchi depth (derived from unpublished data for San Francisco Bay). In most cases we assumed that phytoplankton chlorophyll a was homogeneously distributed in the photic zone; this

Table 1. Summary of data sources used in this study

\begin{tabular}{|c|c|c|c|c|}
\hline Estuary & Type & $\begin{array}{l}\text { Data collection } \\
\text { schedule }\end{array}$ & Source & Comments \\
\hline $\begin{array}{l}\text { South San Francisco } \\
\text { Bay }\end{array}$ & Lagoon & $\begin{array}{l}\text { Monthly in } 1980 \\
\text { Monthly in } 1982\end{array}$ & $\begin{array}{l}\text { Cole \& Cloern } 1984 \\
\text { Cole unpubl. }\end{array}$ & $\begin{array}{l}2 \text { sampling sites } \\
2 \text { sampling sites }\end{array}$ \\
\hline $\begin{array}{l}\text { North San Francisco } \\
\text { Bay }\end{array}$ & River-dominated & Monthly in 1980 & Cole \& Cloern 1984 & 4 sampling sites \\
\hline Puget Sound & Fjord & $\begin{array}{l}\text { Daily during spring } \\
\text { blooms } 1966 \& 1967\end{array}$ & Winter et al. 1975 & $\begin{array}{l}2 \text { sampling sites } \\
\text { Sample activity measured } \\
\text { with a Geiger counter }\end{array}$ \\
\hline South River & Lagoon & $\begin{array}{l}\text { Variable in } 1977 \& \\
1978\end{array}$ & Fisher et al. 1982 & $\begin{array}{l}4 \text { sampling sites } \\
\text { Photic depth calculated from } \\
\text { Secchi depth }\end{array}$ \\
\hline Neuse River & River-dominated & $\begin{array}{l}\text { Variable in } 1977 \& \\
1978\end{array}$ & Fisher et al. 1982 & $\begin{array}{l}1 \text { sampling site } \\
\text { Photic depth calculated from } \\
\text { Secchi depth }\end{array}$ \\
\hline Delaware Bay & River-dominated & $\begin{array}{l}\text { Variable in } 1981 \& \\
1982\end{array}$ & Pennock 1983 & $\begin{array}{l}12 \text { sampling sites } \\
\text { Irradiance measured with a } \\
\text { spherical sensor } \\
\text { Data were excluded when } \\
\text { initial } \mathrm{NH}_{4}^{+} \text {was }<5 \mu \mathrm{M} \mathrm{l}^{-1}\end{array}$ \\
\hline $\begin{array}{l}\text { Hudson River estuary } \\
\text { plume }\end{array}$ & $\begin{array}{l}\text { Coastal transition } \\
\text { zone }\end{array}$ & $\begin{array}{l}\text { Monthly in } 1973 \text { \& } \\
1974\end{array}$ & Malone 1976 & $\begin{array}{l}2 \text { sampling sites } \\
\text { Photic depth calculated from } \\
\text { Secchi depth }\end{array}$ \\
\hline
\end{tabular}


condition is typical in these (Fisher et al. 1982, Pennock 1983, Cloern et al. 1985) and many other shallow estuaries. For Puget Sound and the Hudson river plume, where photic zones are relatively deep and vertical chlorophyll gradients exist (Winter et al. 1975, Malone 1976), B was estimated as the mean chlorophyll a concentration in the photic zone, based on integration of measurements at 4 to 6 depths.

$B$ and $Z_{p}$ are not totally independent variables, because phytoplankton contribute to the attenuation of light. However, estuaries are highly turbid environments such that the contribution of phytoplankton bio- mass to total light attenuation is generally small relative to that of other suspended particulates. For example, in South San Francisco Bay a typical value for the bulk light attenuation coefficient is $1.5 \mathrm{~m}^{-1}$ (Cole \& Cloern 1984) and chlorophyll a concentration is of the order $5.0 \mathrm{mg} \mathrm{m}^{-3}$ (Cole et al. 1986). Based on Bannister's (1974) estimate of light attenuation due to phytoplankton $\left(0.016 \mathrm{~m}^{-1} \mathrm{mg}^{-1} \mathrm{Chl}\right)$, we estimate that only about $5 \%$ of total light attenuation in South San Francisco Bay is attributable to phytoplankton.

All data reported here were collected using similar methods, but as noted below and in Tables $1 \& 2$ there
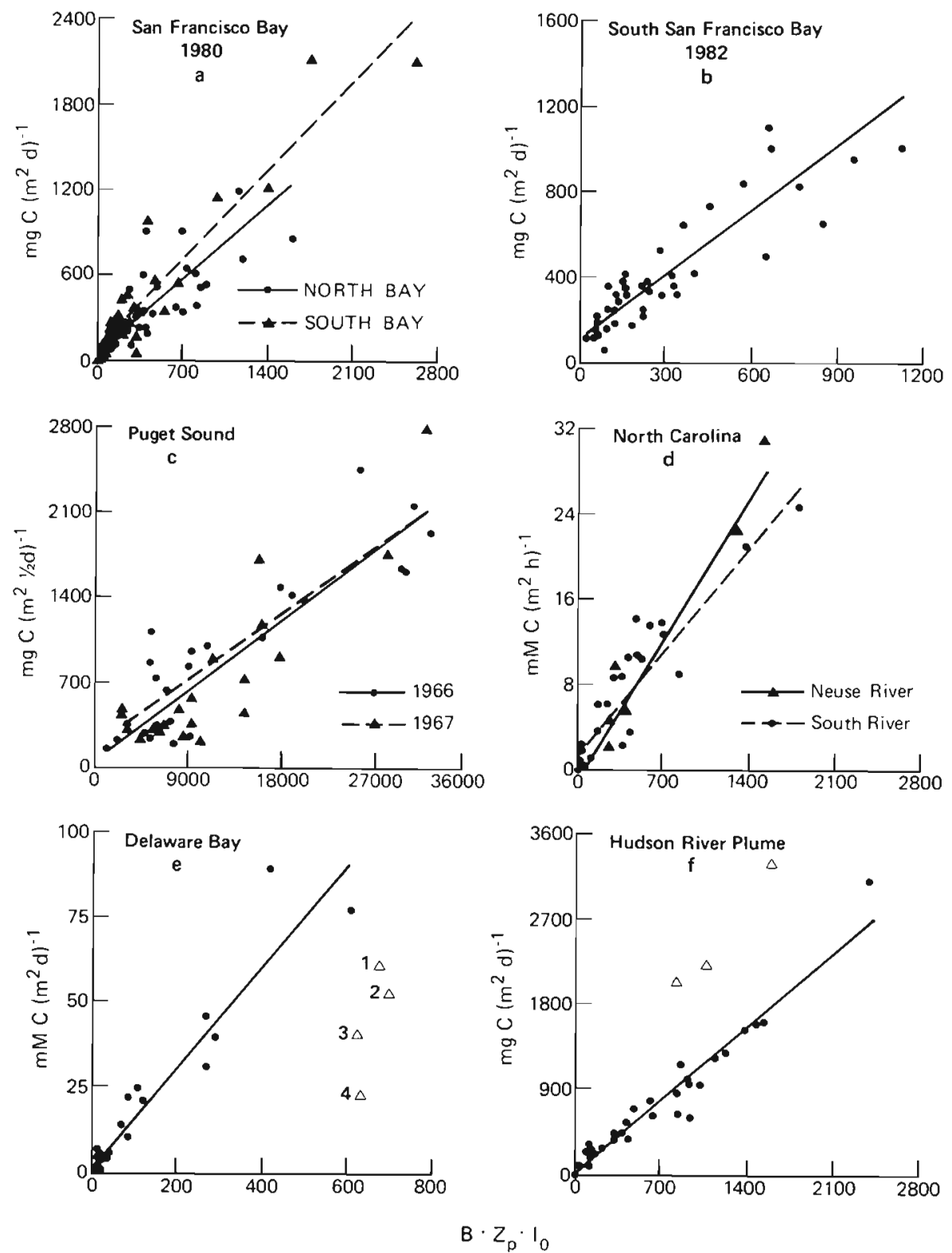

Fig. 1. Regression of photic zone productivity against a composite parameter $B Z_{P} I_{o}$ for each of the 9 data sets included in this study. The units for $B, Z_{p}$, and $I_{0}$ are listed in the footnotes of Table 2 . Points noted with open triangles $(\Delta)$ were not included in regression analyses (see text) 
were differences in experimental techniques and instrumentation that hinder comparison of results among estuaries. In all cases productivity was estimated by measuring carbon-14 assimilation in simulated in situ incubations using natural sunlight. Samples were not prescreened to remove zooplankton except for San Francisco Bay experiments. For each study chlorophyll a was measured fluorometrically (Malone 1976, Fisher et al. 1982, Pennock 1983) or spectrophotometrically (Winter et al. 1975, Cole \& Cloern 1984) using acetone extracts. For Puget Sound experiments the chlorophyll a concentrations were not corrected for phaeopigments and therefore are overestimates of active chlorophyll (Winter et al. 1975).

Ambient irradiance was measured using a variety of instruments. In San Francisco Bay, Neuse River, and South River photosynthetically active irradiance, PAR, was measured with planar $\left(180^{\circ}\right)$ quantum sensors, while in Delaware Bay PAR was measured with a scalar $\left(360^{\circ}\right)$ quantum sensor. Irradiance during experiments in Puget Sound and the Hudson River estuary plume was measured using pyranometers which were not selectively sensitive to PAR.

The general applicability of our empirical model was evaluated by least squares regression of productivity against $B Z_{P} I_{0}$ using pooled data from 6 of the individual data sets. To develop composite parameters based on data collected in different systems but composed of equivalent units, conversions were done on some of the data. Incubation experiments in Puget
Sound were done from noon to sunset. For the combined data set we simply multiplied the half-day irradiance and productivity values by 2 . Radiometric irradiance data for Puget Sound and the Hudson River plume were converted to PAR by applying a correction factor of 0.47 (Vollenweider 1974). Radiometric PAR values (gcal $\mathrm{cm}^{-2} \mathrm{~d}^{-1}$ ) were converted to quantum values $\left(E \mathrm{~m}^{-2} \mathrm{~d}^{-1}\right)$ using a correction factor of 0.192 (Colijn 1982). Accurate conversions could not be made on irradiance data from North Carolina because precise incubation durations were not given. Irradiance data from Delaware Bay also could not be accurately converted to appropriate units because of the difficulty in comparing data collected with spherical and planar sensors. Therefore, data from North Carolina and Delaware Bay were not included in the pooled data set.

\section{RESULTS}

The relation between photic zone productivity and the composite parameter $\mathrm{BZ}_{\mathrm{p}} \mathrm{I}_{0}$ was linear for each system (Fig. 1). In each case the relation was highly significant $(p<0.001)$, except for the Neuse River where $p<0.01$. As indicated by overlapping $95 \%$ confidence intervals for the regression slopes and intercepts (Table 2), there were no significant differences between regressions for the same system using data collected during different years (South San Francisco Bay 1980 and 1982; Puget Sound 1966 and 1967). This

Table 2. Regression parameters $\pm 95 \%$ confidence intervals from linear regressions of productivity against the composite parameter $\mathrm{BZ}_{p} \mathrm{I}_{o}$ for each of the 9 data sets. A: regression intercept; $\mathrm{S}$ : regression slope; $\mathrm{r}^{2}$ : coefficient of determination; $\mathrm{n}$ : number of experiments in the data set. All regressions are significant at $p<0.001$ except for Neuse River where $p<0.01$

\begin{tabular}{|c|c|c|c|c|}
\hline Location & A & S & $r^{2}$ & $n$ \\
\hline \multicolumn{5}{|l|}{ San Francisco Bay ${ }^{1}$} \\
\hline \multirow{2}{*}{$\begin{array}{l}\text { North Bay } 1980 \\
\text { South Bay } 1980\end{array}$} & $63 \pm 56$ & $0.67 \pm 0.12$ & 0.72 & 53 \\
\hline & $94 \pm 88$ & $0.88 \pm 0.12$ & 0.88 & 29 \\
\hline South Bay 1982 & $115 \pm 68$ & $1.02 \pm 0.16$ & 0.78 & 44 \\
\hline \multicolumn{5}{|l|}{ Puget Sound ${ }^{2}$} \\
\hline 1966 & $56 \pm 296$ & $0.065 \pm 0.020$ & 0.60 & 29 \\
\hline 1967 & $168 \pm 204$ & $0.061 \pm 0.012$ & 0.79 & 25 \\
\hline \multicolumn{5}{|l|}{ North Carolina ${ }^{3}$} \\
\hline \multirow{2}{*}{$\begin{array}{l}\text { South River } \\
\text { Neuse River }\end{array}$} & $1.46 \pm 1.38$ & $0.00014 \pm 0.00002$ & 0.84 & 27 \\
\hline & $-0.94 \pm 3.66$ & $0.00019 \pm 0.00004$ & 0.94 & 6 \\
\hline Delaware Bay ${ }^{4}$ & $1.22 \pm 3.24$ & $0.15 \pm 0.018$ & 0.91 & 27 \\
\hline Hudson River Plume' & $-14 \pm 88$ & $1.14 \pm 0.10$ & 0.94 & 31 \\
\hline Productivity & Biomass & Photic depth & Irradiance & Incubation duration \\
\hline${ }^{1} \mathrm{mg} \mathrm{C} \mathrm{m}^{-2} \mathrm{~d}^{-1}$ & $\mathrm{mg} \mathrm{Chl} a \mathrm{~m}^{-3}$ & $\mathrm{~m}$ & $E m^{-2} d^{-1}\left(180^{\circ}\right)$ & $24 \mathrm{~h}$ \\
\hline${ }^{2} \mathrm{mgCm} \mathrm{m}^{-2} 1 / 2 \mathrm{~d}^{-1}$ & $\mathrm{mgChla \textrm {m } ^ { - 3 }}$ & $\mathrm{m}$ & gcal cm-2 $1 / 2 \mathrm{~d}^{-1}$ & Noon-sunset \\
\hline${ }^{3} \mathrm{mM} \mathrm{C} \mathrm{m}^{-2} \mathrm{~h}^{-1}$ & mg $C h l a \mathrm{~m}^{-3}$ & $\mathrm{~m}$ & $E \mathrm{~m}^{-2} \mathrm{~s}^{-1}$ & 1 to $6 \mathrm{~h}$ \\
\hline $\mathrm{mMC} \mathrm{m} \mathrm{m}^{-2}$ & $\mathrm{mg} \mathrm{Chl} \mathrm{a} \mathrm{m}^{-3}$ & $\mathrm{~m}$ & $E \mathrm{~m}^{-2} \mathrm{~d}$ & $24 \mathrm{~h}$ \\
\hline
\end{tabular}




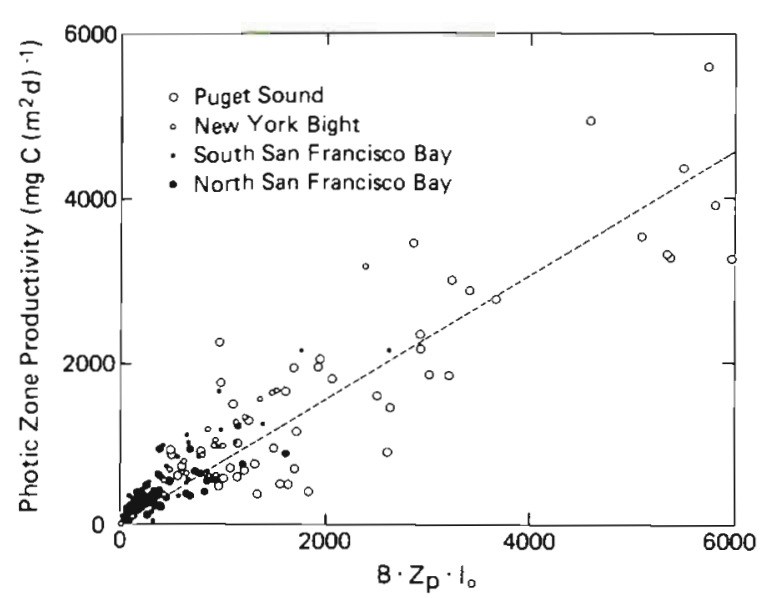

Fig. 2. Regression of photic zone productivity against the composite parameter $B Z_{p} l_{0}$ for 211 incubation experiments. $\mathrm{P}=150+0.73\left(\mathrm{BZ}_{\mathrm{p}} \mathrm{I}_{0}\right) ; \mathrm{r}^{2}=0.82 ; \mathrm{S}_{\mathrm{yx}}$ (standard error of the estimate) $=410$

suggests that over annual cycles (e. g. San Francisco Bay, South River, Neuse River, Delaware Bay, and Hudson estuary plume), or between years a single function can predict well changes in photic zone productivity. The mean coefficient of determination $r^{2}$ for the 9 data sets was 0.82 .

There was also a highly significant relation $(p<0.001)$ between productivity and $B Z_{p} I_{o}$ (Fig. 2) for the pooled data $(n=211)$. The coefficient of determination for the 6 combined data sets was the same as that for the 9 individual regressions $\left(\mathrm{r}^{2}=0.82\right)$. Thus, $82 \%$ of the variance in productivity, over the diverse range of growth conditions and phytoplankton populations encompassed by these 6 data sets from 12 sites in 4 estuarine systems, can be accounted for by variations in the composite parameter. Consequently, a single regression function can be used to estimate productivity in a wide range of temperate estuarine environments.

\section{DISCUSSION}

The strong correlation between $\int \mathrm{P}$ and $\mathrm{B} \mathrm{Z}_{\mathrm{p}} \mathrm{I}_{o}$ indicates an overriding importance of biomass and light to governing large-scale variations in productivity in these estuaries. For the 6 estuaries and the estuarine plume included in this analysis, typically more than $80 \%$ of the spatial and temporal variability in productivity is correlated with variations in 3 easily measured parameters: phytoplankton chlorophyll $a$, photic depth, and surface irradiance. This finding is similar to that of Brylinsky \& Mann (1973) for lakes. In both studies a combination of biological and light-energy related parameters has been found to be of major importance in determining productivity. Likewise, models proposed by Wofsy (1983) and Platt (1986) suggest that in eutrophic and oceanic waters primary productivity, normalized to phytoplankton biomass, is largely dependent on light availability. Wofsy (1983) developed a mechanistic model to estimate watercolumn primary production in rivers and estuaries, based upon estimates of phytoplankton growth and light attenuation partitioned between phytoplankton and detritus. The model used in our study was derived empirically (Cole \& Cloern 1984, Cole et al. 1986), although Platt (1986) explains the mechanistic foundation of such an approach. He similarly concludes that biomass-specific production in the ocean is a linear function of surface light intensity.

Photosynthesis is a complex and highly variable process. Numerous studies have documented hourly and daily variations in carbon assimilation rates. We know that specific rates of phytoplankton photosynthesis $\left(\mathrm{P}_{\mathrm{m}}^{\mathrm{B}}\right.$, specific productivity at saturating light intensity; and $\alpha$, the initial slope of the light-saturation curve) vary with recent light history (Dubinsky 1980, Falkowski 1980, 1981, Neale \& Marra 1985), temperature (Krawiec 1982, Côté \& Platt 1983, Miller \& Kamykowski 1986), spectral quality of light (Walsh \& Legendre 1983), and salinity (Krawiec 1982, Miller \& Kamykowski 1986). By necessity, such studies were conducted over short time periods at a limited number of sites. Consequently, the implications of such studies may not be relevant to changes in production throughout estuarine systems over time scales of weeks to years. Deviation of individual data points from the regression lines in Fig. $1 \& 2$ implies that there are daily variations in productivity caused by factors other than biomass and light availability (e.g. carbon assimilation rate). However, our analysis of all productivity data collected throughout a bloom or an annual cycle suggests that over periods of weeks to years and over large geographic areas the influence of short-term physiological variability $\left(\mathrm{P}_{\mathrm{m},}^{\mathrm{B}} \alpha\right)$ on estuarine productivity is relatively small and not systematically related to variability in $B, I_{o}$ and $Z_{p}$. Thus, the model is useful to systems ecologists, fishery biologists, geochemists, and other researchers concerned with the seasonality of primary productivity throughout estuaries, but of limited usefulness to phytoplankton physiologists.

\section{Model implications and utilities}

Because a single formulation gives reasonable estimates of productivity (Fig. $1 \& 2$ ), large-scale spatial variability of productivity can be determined from a few measures of productivity (to generate the $\int \mathrm{P} v s \mathrm{~B}$ $\mathrm{Z}_{\mathrm{p}} \mathrm{I}_{\mathrm{o}}$ line) and many measures of $\mathrm{B}$ and $\mathrm{Z}_{\mathrm{p}}$ over a large geographic area. Use of this model should give more robust estimates of estuarine productivity than the traditional approach of using measured productivity at 
a few sites to represent productivity throughout an estuarine system. This utility could be extended to provide high-resolution mapping of estuarine productivity using remote sensing techniques. Some success has been made in mapping turbidity $\left(Z_{p}\right)$ and chlorophyll a concentration in estuaries and coastal waters (Khorram 1981, Hilton 1984). The Airborne Ocean Color Imager, for example, has sensors for wavebands specifically required to estimate turbidity and chlorophyll and the instrument can be configured to yield high resolution (i. e. $50 \mathrm{~m} \times 50 \mathrm{~m}$ ) measures of reflectance at the required wavelengths. Simultaneous measures of productivity at a finite number of sites (again to determine the $\int \mathrm{P} v s \mathrm{BZ}_{\mathrm{p}} \mathrm{I}_{\mathrm{o}}$ line) would then yield a capability of mapping productivity in detail over an entire estuary or river plume.

The model is also useful for determining those instances when factors other than biomass and light are important controls on productivity. The relation between $\int \mathrm{P}$ and $\mathrm{BZ}_{\mathrm{p}} \mathrm{I}_{0}$ was relatively constant in the nutrient-rich systems included in this study (Table 2). Therefore, measured productivity values that differ significantly from those predicted using the regression model might indicate instances where secondary factors are influencing productivity. The data we evaluated, except for Delaware Bay, were from systems where nutrient concentrations are not believed to typically limit production (Winter et al. 1975, Malone 1976, Fisher et al. 1982, Pennock 1983, Cole \& Cloern 1984). Thus the regressions listed in Table 2 predict productivity under nutrient-replete conditions. If measured productivity for an individual experiment is significantly greater than predicted by the composite parameter one might suspect that abnormally high carbon or nutrient assimilation rates affected the results. When productivity is less than predicted using the regression model, factors such as nutrient limitation, abnormally low assimilation rates or toxins may be indicated. Obviously, experimental error may also be suggested when measured values differ significantly from predicted levels of productivity.

The data from the Hudson River estuary plume (Fig. 1f) include 3 instances when productivity may have been abnormally enhanced by high carbon assimilation rates or high temperatures. Chlorophyll-specific assimilation rates for each of these 3 experiments were 4 to 5 times greater than average values from the Hudson River plume, and nearly twice that of the next highest assimilation rate measured during the study. However, incubation temperatures were also 2 to $5 \mathrm{C}^{\circ}$ above ambient water temperatures ( $T$. Malone pers. comm.). Therefore, the data were of questionable accuracy and were not included in Malone's (1976) report. The positions of these 3 points relative to the other data in Fig. 1f support that decision.
Similarly, the positions of 4 data points relative to the other data from Delaware Bay (Fig. 1e) suggest that factors besides phytoplankton biomass and light availability were responsible for productivity being lower than expected.Three of the 4 data points deleted from the Delaware Bay regression had maximum carbon assimilation rates $\left(\mathrm{P}_{\mathrm{m}}^{\mathrm{B}}\right)$ that were anomalously low. $P_{m}^{B}$ values were 1 to $50 \%$ of those reported for nearby sites. There was no apparent reason for the low productivity value associated with point \#4. Deviation of the measured rate from predicted productivity may indicate experimental or measurement error, or may indeed be real. In any case, the positions of these 4 points relative to others of the data set leads one to suspect that unusual factors have influenced the measured productivity.

In summary, the linear relation and high degree of similarity between regressions of productivity and the composite parameter for data collected in a variety of systems has 2 major implications. First, it suggests that a simple empirical equation can be used to estimate changes in daily productivity over seasonal or annual time periods throughout an individual estuary or to compare productivity in different systems. Thus, the pooled data model and the models for individual systems represent tools that may be of utility to ecologists and geochemists studying seasonal or annual processes related to primary productivity (nutrient uptake, secondary production, dissolved oxygen dynamics, etc.). Second, instances when measured productivity differs widely from that predicted using the composite parameter model may indicate that secondary factors are significantly affecting the measured rates, or that there was experimental error in one of the analyses.

Acknowledgements. We gratefully acknowledge the generosity of T. Malone and J. Pennock who provided tabulations of their data, and J. Postel and K. Banse for providing data collected by $\mathrm{D}$. Winter and his co-workers. We also appreciate useful discussions with S. Hager, P. Neale, and suggestions from an anonymous referee who reviewed an earlier draft of the manuscript.

\section{LITERATURE CITED}

Bannister, T. T. (1974). A general theory of steady state phytoplankton growth in a nutrient saturated mixed layer. Limnol. Oceanogr. 19: 13-30

Boynton, W. R., Kemp, W. M., Keefe, C. W. (1982). A comparative analysis of nutrients and other factors influencing estuarine phytoplankton production. In: Kennedy, V S. (ed.) Estuarine comparisons. Academic Press, New York, p. 69-90

Brylinsky, M., Mann, K. H. (1973). An analysis of factors governing productivity in lakes and reservoirs. Limnol Oceanogr, 18: 1-14

Cadée, G. C. (1978). Primary production and chlorophyll in the Zaire River, estuary and plume. Neth. J. Sea Res. 12: 368-381 
Cadée, G. C., Hegeman, J. (1974). Primary production of phytoplankton in the Dutch Wadden Sea. Neth. J. Sea Res. 8: $240-259$

Cloern, J. E. (1984). Temporal dynamics and ecological significance of salinity stratification in an estuary (South San Francisco Bay, USA). Oceanologica Acta 7: 137-141

Cloern, J. E., Cole, B. E., Wong, R. L. J., Alpine, A. E. (1985). Temporal dynamics of estuarine phytoplankton: a case study of San Francisco Bay. Hydrobiologia 29: 153-176

Cole, B. E., Cloern, J. E., Alpine, A. E. (1986). Biomass and productivity of three phytoplankton size classes in San Francisco Bay. Estuaries 9: 117-126

Cole, B. E., Cloern, J. E. (1984). Significance of biomass and light availability to phytoplankton productivity in San Francisco Bay. Mar. Ecol. Prog. Ser. 17: 15-24

Colijn, F. (1978). Primary production measurements in the Ems-Dollard estuary during 1975 and 1976. Publikates en Verslagen 1: 1-14

Colijn, F. (1982). Light absorption in the waters of the EmsDollard estuary and its consequences for the growth of phytoplankton and microphytobenthos. Neth. J. Sea Res. 15: $196-216$

Colijn, F., Ludden, E. (1983). Primary production of phytoplankton in the Ems-Dollard estuary. In: Colijn, F. (ed.) Primary production in the Ems-Dollard estuary. Drukkerij Van Denderen, Groningen, p. 38-99

Côté, B., Platt, T. (1983). Day-to-day variations in the springsummer photosynthetic parameters of coastal marine phytoplankton. Limnol. Oceanogr. 28: 320-344

Dubinsky, Z. (1980). Light utilization efficiency in natural phytoplankton communities. In: Falkowski, P. G. (ed.) Primary productivity in the sea. Plenum Press, New York, p. 83-97

Falkowski, P. G. (1980). Light-shade adaptation in marine phytoplankton. In: Falkowski, P. G. (ed.) Primary productivity in the sea. Plenum Press, New York, p. 99-119

Falkowski, P. G. (1981). Light-shade adaptation and assimilation numbers. J. Plankton Res. 3: 203-216

Fisher, T. R., Carlson, P. R., Barber, R. T. (1982). Carbon and nitrogen primary productivity in three North Carolina estuaries. Estuar. coast. Shelf Sci. 15: 621-644

Haas, L. W., Hastings, S. J., Webb, K. L. (1981). Phytoplankton response to a stratification-mixing cycle in the York River estuary during late summer. In: Neilson, B. J., Cronin, L. E. (ed.) Estuaries and nutrients. Humana Press, Clifton, New Jersey, p. 619-636

Harris, G. P. (1978). Photosynthesis, productivity and growth: The physiological ecology of phytoplankton. Arch. Hydrobiol. 10: 1-171
Hilton, J. (1984). Airborne remote sensing for freshwater and estuarine monitoring. Wat. Res. 18: 1195-1223

Joint, I. R., Pomroy, J. (1981). Primary production in a turbid estuary. Estuar. coast. Shelf Sci. 13: 303-316

Khorram, S. (1981). Water quality mapping from Landsat digital data. Int. J. Remote Sensing 2: 145-153

Krawiec, R. (1982). Autecology and clonal variability of the marine centric diatom Thalassiosira rotula (Bacillariophyceae) in response to light, temperature and salinity. Mar. Biol. 69: 79-89

Malone, T. C. (1976). Phytoplankton productivity in the Apex of the New York Bight: environmental regulation of productivity/chlorophyll a. Limnol. Oceanogr. Symposium 2: 260-272

Miller, R. L., Kamykowski, D. L. (1986). Effects of temperature, salinity, irradiance and diurnal periodicity on growth and photosynthesis in the diatom Nitzschia americana: light-limited growth. J. Plankton Res. 8: 215-228

Neale, P. J., Marra, J. (1985). Short-term variation of $P_{\max }$ under natural irradiance conditions: a model and its implications. Mar. Ecol. Prog. Ser. 26: 113-124

Nixon, S. W. (1981). Freshwater inputs and estuarine productivity. In: Cross, R., Williams, D. (ed.) Proceedings of the National Symposium on Freshwater Inflow to Estuaries. U.S. Fish and Wildlife Service, p. 31-57

Pennock, J. R. (1983). Regulation of phytoplankton carbon and nitrogen production in the Delaware estuary. Ph. D. thesis, University of Delaware

Peterson, D. H., Festa, J. F. (1984). Numerical simulation of phytoplankton productivity in partially mixed estuaries. Estuar. coast. Shelf Sci. 19: 563--589

Platt, T. (1986). Primary production of the ocean water column as a function of surface light intensity: algorithms for remote sensing. Deep Sea Res. 31: 1-11

Sinclair, M. (1978). Summer phytoplankton variability in the lower St. Lawrence estuary. J. Fish. Res. Bd Can. 35: $1171-1185$

Vollenweider, R. A. (1974). A manual on methods for measuring primary production in aquatic environments. Blackwell Scientific Publications, Oxford

Walsh, P., Legendre, L. (1983). Photosynthesis of natural phytoplankton under high frequency light fluctuations simulating those induced by sea surface winds. Limnol. Oceanogr. 28: 688-697

Winter, D. F., Banse, K., Anderson, G. C. (1975). The dynamics of phytoplankton blooms in Puget Sound, a fjord in the Northwestern United States. Mar. Biol. 29: 139-176

Wofsy, S. C. (1983). A simple model to predict extinction coefficients and phytoplankton biomass in eutrophic waters. Limnol. Oceanogr. 28: 1144-1155

This article was submitted to the editor; it was accepted for printing on December 22, 1986 